\title{
Difficulties of Persian Learners of English in Pronouncing Some English Consonant Clusters
}

\author{
Mohamad Ali Fatemi ${ }^{1}$, Atefe Sobhani ${ }^{1{ }^{1 *}}$ \& Hamzeh Abolhassani ${ }^{2}$ \\ ${ }^{1}$ Department of English, Torbat-e-Heydareih Branch, Islamic Azad University (IAU), Torbat-e-Heydareih, Iran \\ ${ }^{2}$ Department of English, Hakim Sabzevari University, Sabzevar, Iran \\ *Corresponding author: Torbat-e-Heydareih Branch, Islamic Azad University (IAU), Iran \\ E-mail: Atefe.Sobhani@gmail.com
}

Received: September 4, 2012

Accepted: December 3, 2012 Online Published: December 15, 2012

doi:10.5430/wjel.v2n4p69

URL: http://dx.doi.org/10.5430/wjel.v2n4p69

\begin{abstract}
The present study aims to investigate some difficulties that Persian EFL learners may have in producing some English consonant clusters orally. Since consonant clusters in a language comply with its underlying phonological rules, or more specifically underlying syllabic structure, it seems to be quite relevant to deal with the syllabic structural rules of first and second languages.

It could be hypothesized that learners when facing such structural unfamiliarities resort to their native language phonological rules. By taking contrastive analysis hypothesis $(\mathrm{CAH})$ into account, we could get a clearer vision partly towards the difficulties to reject or confirm the hypothesis.
\end{abstract}

Keywords: consonant clusters; syllabic structure; $C A H$

\section{Introduction}

Mispronunciation can be a reason why sometimes a conversation leads to failure; hence, phonology which is considered a component of grammatical competence subcategorized within communicative competence. (Brown, 2007)

Aside from unintelligibility, pronunciation could identify the speaker as a nonnative speaker of a language, a phenomenon which arises from a person's native accent (Richards \& Schmidt, 2010). Consonant cluster is defined in Longman Dictionary of Language Teaching and Applied Linguistics as a set of consonants at the beginning or at the end of a syllable or at the end of the issues related to clustering consonants. It refers to the fact that as languages differ, clusters can be made differently by consonants (Celce-Murcia, Brinton, Goodwin \& Griner, 2010). This study first is going to review some previous studies. Then, establish some definitions on syllable and its components. Moreover, it investigates the structures of syllables in both languages, English and Persian. There is also a background presented on $\mathrm{CAH}$ to establish the basis for data analysis.

\section{Literature Review}

\subsection{Previous studies on consonant clusters}

Jabbari and Samavarchi (2011) discussed syllabification of English consonant clusters by Persian Learners. Children who were at the initial state of second language learning were chosen as the participants of the study. They involved in an oral production task in which the words said by the author twice and children were asked to repeat the words individually. This task was recorded to see if there were a similarity between the first and the second repetition. The result revealed that the learners re-syllabified syllable-initial clusters when they use epenthesis instead of deletion, so one syllable was re-syllabified into two (two-consonant clusters), three or four syllables. This was a negative transfer from Persian. 
The article done by (Kabak \& Idsardi, 2007) investigated the perceptual distortions in the adaptation of English consonant clusters by Korean speakers. This study aimed to illustrate if perceptual epenthesis was the result of all kinds of illicit sequences of consonants, contact violations would be changed perceptually. Additionally, they wanted to show the cause of perceptual distortions. The results of the research elicited that it was the syllable structure restrictions which induced perceptual epenthesis in L2 and perception of epenthesis vowels rather than consonantal contact restrictions. Moreover, it was demonstrated that the voice was dangled in Korean listeners' representations. Furthermore, the findings displayed that for repairing and changing misplaced sequences of consonants, Korean listeners didn't apply some phonological phenomena such as neutralization, lateralization, and nasalization processes.

Chang (2004) studied the errors which happened in processing consonant clusters of Chinese learners of English as a foreign language. The data collected from the subjects who were involved in six phonological processing tasks such as syllable deletion and phoneme deletion. This procedure was recorded. The study indicated that due to contrastive analysis hypothesis, Chinese syllable structure contains only one consonant in the onset, but English syllable structure includes three consonants in the onset. According to this syllable complexity, Chinese learners encounter problems as a consequence of interference from native language. Based on the results of this research six types of errors were observed such as epenthesis, considering a cluster as a single unit, omission of the second of an initial two-element cluster. Moreover, some errors were found that they were caused by some developmental factors rather than interference from native language.

Byrd and Tan (1996) studied the increasing speech rate due to consonant clusters. In this research the duration of consonants, latency and overlap between them, and displacement of consonants were investigated. They reported since the duration of each component of a sequence or individual consonant was reduced, it could be considered as a mechanism of quick speech rate. Moreover, the coarticulation or the overlap of articulations would be another mechanism. Furthermore, it was illustrated that some other factors such as manner and place of a consonant influenced the speech rate.

Consonant clusters are the structures which are rare and they are not found in the majority of the languages'phonotactic systems in the world. Hence, consonant clusters could be called uncommon structures (Greenberg, 2005; Schreier, 2005).

Persian learners of English encounter difficulty in pronunciation of initial consonant clusters since there are not initial consonant clusters in Persian. They add a vowel before the cluster or between that to pronounce it easier (Keshavarz, 2001). Thus, initial consonant clusters are not allowed by Persian (Yarmohammadi, 2002). Sometimes, Persian speakers omit one of the consonants of a final cluster which is made of three consonants. It's another way to simplify difficult consonant clusters (Keshavarz, 2001).

\subsection{Syllable Differences across Languages}

Before dealing with different forms of syllable and how they are different across the languages we need to have some definitions and grounds firmed and cleared. Maybe a definition of syllable by Longman Dictionary of Language Teaching and Applied Linguistics is a good start. Syllable is a phonological unit of speech consisting of one vowel which is called a nucleus and preceded by a consonant or a consonant cluster considered as onset and it is followed by a coda that is a consonant or consonant cluster. The rhyme includes the coda and nucleus (Davies \& Elder, 2004). To make things more comfortable $\mathrm{C}$ stands for consonant and $\mathrm{V}$ for vowel.

Consequently, we can infer from the definitions presented that the structure of a syllable at most consists of three components: onset, nucleus, and coda.

According to Davies and Elder (2006), in some languages, there are some syllables having no coda; however, all syllables have a nucleus. There is a fact of an awareness of phonological knowledge since native speakers of a language start to syllabize a word or count the number of syllables of a word. Thus, it would not be in contrast with their phonological rules (O'Grady, Katamba \& Archibald, 2011). Furthermore, distribution of slot fillers (consonants and vowels) in the positions of onset, nucleus, or coda is something which obeys certain rules known as phonological rules that are different from one language to another.

\subsection{Persian Syllabic Structure}

According to Samareh (1999) a syllable is a string of phonemes consisting of one vowel and one to three consonants in which the vowel (not more than one vowel and not a consonant) is always the nucleus and a consonant is always present in onset position and consonant(s) most often appear in the coda position. 
There are three sorts of syllable forms according to the distribution of Cs and Vs in Persian: CV, CVC, and CVCC. To make it brief the possibility of syllable occurrence is $\mathrm{CV}(\mathrm{C})(\mathrm{C})$.

To clarify the point, Table 1 is presented which shows the syllabic structures of some Persian words. Since Persian syllable does not take an initial vowel, the least components necessary for a syllable is CV structure, it means a consonant in onset position and a vowel as the nucleus (Salmani-Nodoushan, 2006).

Table 1:

\begin{tabular}{|c|c|c|}
\hline The Persian Word & Pronunciation & Syllabic Structure \\
\hline $\begin{array}{c}\text { بأ 'with' } \\
\text { 'wit }\end{array}$ & /ba/ & $\mathrm{CV}$ \\
\hline 'little' & /kam/ & $\mathrm{CVC}$ \\
\hline 'man' & $/ \mathrm{mard} /$ & CVCC \\
\hline $\begin{array}{c}\text { سفره 'table cloth' } \\
\text { ' }\end{array}$ & /sof.re/ & CVC.CV \\
\hline 'recognition' & $/ \int$ e.naxt/ & CV.CVCC \\
\hline
\end{tabular}

As it can be clearly seen, consonant clustering just occurs in coda position. In less technical words, there is no word initiating with a consonant cluster. Also, there is no word ending three consonants or more which means that there are no more than two consonants in final consonant cluster in a syllable (Salmani-Nodoushan, 2006).

\subsection{English Syllabic Structure}

The most common type of syllable in English is CV (e.g. to). A syllable consists of onset and the rime. The rime consists of the vowel plus any following consonants. English can have as many as three consonants before and four consonants after the vowel. We can show the possibility of the occurrence of an English syllable as follows: $(C)(C)(C) V(C)(C)(C)(C)$. Syllable-initial consonant clusters and syllable-final consonant clusters are possible (Salmani-Nodoushan, 2006).

According to this definition the necessary and obligatory component in an English syllable is its nucleus, the vowel phoneme. Consonants are all optional. To illustrate some examples of English words, Table 2 presented all the possibilities of English syllable structure.

Table 2:

\begin{tabular}{|c|c|c|}
\hline English syllable Structure & \multicolumn{2}{|c|}{ Words and Pronunciation } \\
\hline $\mathrm{V}$ & Eye & /ai/ \\
\hline $\mathrm{VC}$ & an & /æn/ \\
\hline VCC & ant & /ænt/ \\
\hline $\mathrm{VCCC}$ & ants & /ænts/ \\
\hline $\mathrm{CV}$ & key & /ki:/ \\
\hline $\mathrm{CVC}$ & beg & /beg/ \\
\hline CVCC & nest & /nest/ \\
\hline $\mathrm{CCV}$ & clue & /klu:/ \\
\hline CCVC & steep & /sti:p/ \\
\hline CCVCC & flask & /flæsk/ \\
\hline CCVCCC & flasks & /flæsks/ \\
\hline CCVCCCC & trampled & /træmpld/ \\
\hline $\mathrm{CCCV}$ & scree & /skri:/ \\
\hline CCCVC & screen & /skri:n/ \\
\hline CCCVCC & straddle & /strædl/ \\
\hline CCCVCCC & strangle & /strængl/ \\
\hline CCCVCCCC & strengths & /strengths/ \\
\hline
\end{tabular}




\subsection{Contrastive Analysis Hypothesis (CAH)}

Contrastive analysis hypothesis tries to predict students' errors through finding similarities and differences between students' native language and the target language. (Brown 2007)

Lado (1957, cited in Brown, 2007) made one of the strongest claims in CAH domain. In Linguistics Across Cultures, he stated that by considering the native language and culture of the students, we can compare them with the culture and language which is supposed to be learned. Thus, it is possible to make prediction and give an account of the patterns which will induce difficulty and those which will not induce difficulty in learning. In another section of his book, Lado indicated that by comparing the elements of foreign language with those of native language, we can conclude that the elements which are similar to native language are easy to learn while elements which are different from native language would be difficult. As some researchers argued these claims were regarded as an empirical method of prediction.

Stockwell, Bowen, and Martin (1965) made a model entitled "the hierarchy of difficulty". According to principles of transfer and obligatory and optional choices of specific phonemes, six levels of difficulties were proposed by them to predict difficulty of a certain aspect of the second language. Brown considered these levels as following: Level 0 (Transfer), Level 1 (Coalescence), Level 2 (Under differentiation), Level 3 (Reinterpretation), Level 4 (Over differentiation), and Level 5 (Split). Since level 4 is more related to the present study and we will refer to it in analysis section, there is more elaboration on level 4 below:

Level 4 or Over differentiation happens when there is an item with little similarity to the native language or an item which is absent in the native language (Brown, 2007; Ziahosseiny, 2009). For example, when an English speaker learns Spanish, he is supposed to learn grammatical gender inherent in nouns (Brown, 2007).

The objectives of the investigation can be expressed in the following research question:

Do Persian learners of English encounter some difficulties in pronouncing English consonant clusters?

\section{Methodology}

\subsection{Participants}

The subjects were 30 female and male students randomly chosen from 3 classes at Qeshm English Language Institute in Mashhad, Iran. Participants were EFL learners at intermediate level. They were Persian native speakers whose age ranged between 18-30 years old. Students participated in a test and read some sentences.

\subsection{Instrument}

The instrument used in the current study to collect data was a test which comprised six sentences. Each sentence included at least two clusters and the total number of these clusters was fourteen. Students were required to read the sentences. The researchers also make use of an MP4 to record learners' oral production.

\subsection{Procedure}

At first 30 students from 3 classes were chosen randomly. All of them were tested individually in a relatively quiet room at institute and the test took a few minutes for each student. For further concentration on the way the words (not the whole sentence) articulated by the participants, just the words (not the complete sentences) were recorded and transcribed by the researchers to be analyzed then. The order in all phonetic transcripts is as their phonemic transcripts in the sentences as followes: <prove $>,<$ stole $>,<$ plant $>,<$ strength $>,<$ breadth $>$, $<$ principles $>$, $<$ facts $>,<$ trainer $>$, $<$ spoke $>$, $<$ class $>$, $<$ scratch $>,<$ spray $>$, $<$ clothes $>,<$ flight $>$.

\section{Results}

The productions of 15 students, which were transcribed, were selected as a sample in table 3 . The transcription of each subject was separated from others by assigning each student's production a number on the left. 
Table 3:

1. /pru:v/,/stul/, /plant/, /strend3/, /brI /, /pərinsi:plz/, /fakts/, /treiner/, /espok,/

/klas/, /eskrat/, /esprey/, /kloses/, /flait/.

2. /peruved/, /estol/, /pla:nt/, /stra:n日/,/brez/, /perenikiplz/, /flaks/, /treiner/, /spok/, /klas/, /escreiz/, /esproi/, /keloz/, /fait/.

3. /porovd/, /stərl/, /plan/, /estren $\theta /$, /bre $\theta /$, /prensiplz/, /faks/, /triner/, /espok/

/klas/, /eskrat/, /sprei/, /koloz/, /flait/.

4. /pru:vd/, /estol/, /pla:nt/, /stren $\theta /$, /beraz/, /pirinsipl/, /faks/, /treiner/,/spok/, /klas/, /eskrat/, /esprei/, /keloz/, /flait/.

5. /puru:vd/, /estol/, /pelant/, /estren/, /beredz/, /pirinciplz/, /fakts/, /tereiner/, /espok/, /kəlas/, /eskrat/, /esperei/, /keloz/, /felait/.

6. /poruvd/, /estol/, /pelant/, /estrend3/, /bris/, /pirinsipel/, /fakts/, /tereiner/, /espok/, /klas/, /estrat/,/sprei/,/keloz/, /felait/.

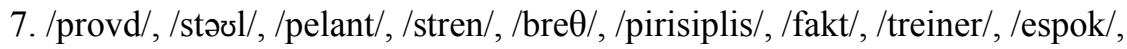
/klas/, /estrat/, /sprei/, /kloz/, /flait/.

8. /peruved/, /stol/, /plant/, /stren/, /bris/, /pirinsipel/, /fakts/, /tereiner/, /espok/, /klas/, /eskrat/, /esprei/, /keloz/, /felait/.

9. /poruvd/, /estol/, /pelant/, /estrend3/, /bred0/, /pirisiplis/, /fakt/, /tereiner/, /spok/, /klas/, /eskrat/, /esprey/, /kelos/, /felait/.

10. /puru:vd/, /estol/, /pelant/, /stren/, /beraz/, /pirinsipel/, /faks/, /treiner/, /espok/, /klas/, /eskrat/, /esprey/, /keloz/, /fait/.

11. /peruved/, /stul/, /pla:nt/, /stra:n日/, /bris/, /porinsi:plz/, /fakts/, /tereiner/, /espok/, /kəlas/,/eskrat/, /esprei/, /kelos/, /flait/.

12. /porovd/, /estol/, /pelant/, /stren $\theta /$, /bre $\theta /$, /prensiplz/, /faks/, /tereiner/, /espok/, /klas/,/estrat/,/sprei/,/kloz/, /flait/.

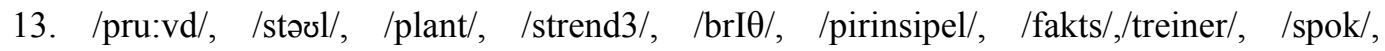
/klas/,/escreiz/, /esproi/, /kloses/, /felait/.

14. /provd/, /stol/, /pla:nt/, /stren/, /berez/, /pirinsipl/, /faks/, /triner/, /espok/, /klas/,/estrat/, /sprei/, /keloses/, /flait/.

15. /pru:v/, /estol/, /pelant/, /strend3/, /brI $/$ /, /perenikiplz/, /fakt//treiner/, /espok/, /kəlas/, /eskrat/, /sprei/,/kelozez/, /felait/.

The data collected were analyzed according to three phonological processes: epenthesis, prosthesis, and deletion. It is presented in Table 4 and Table 5.

Table 4:

\begin{tabular}{cccccc}
\hline Word & Epenthesis & Prothesis & Word & Epenthesis & Prothesis \\
\hline Proved & 9 & - & scratch & - & 15 \\
Stole & - & 8 & spray & - & 9 \\
Plant & 8 & - & clothes & 11 & - \\
Trainer & 7 & - & flight & 6 & - \\
Spoke & - & 11 & class & 3 & - \\
\hline
\end{tabular}


Table 5:

\begin{tabular}{ccccc}
\hline Word & Prothesis & $\begin{array}{c}\text { Epenthesis } \\
\text { (in onset) }\end{array}$ & $\begin{array}{c}\text { Epenthesis } \\
\text { (in coda) }\end{array}$ & $\begin{array}{c}\text { (Consonant) } \\
\text { Deletion }\end{array}$ \\
\hline Facts & - & - & - & 9 \\
strength & 3 & - & - & 13 \\
breadth & - & 4 & - & 6 \\
principles & - & 13 & 7 & - \\
\hline
\end{tabular}

Here it seems to be useful to have a brief definition of each new term that the data is categorized based on them within the tables. Epenthesis occurs when in a certain environment of a word, a segment, either vowel or consonant, is added (Malmkjær, 2010). Prothesis is used to facilitate the pronunciation of an initial consonant cluster by adding a segment at the beginning of a word. Deletion is the last process in which a sound or morpheme, or a word is left out from what is said by the speakers (Richards \& Schmidt, 2010).

Persian learners of English, especially those experiencing their first levels of language learning, while facing a structure in contrast with their mother tongue resort to L1 (Persian) to compensate for their lack of proficiency and to deal with the challenge. This could be supported by CAH. Persian learners when have problems in pronouncing an English syllable which has little or no similarity to Persian syllable $((\mathrm{C}) \mathrm{CCV}$ or $(\mathrm{C})(\mathrm{C})(\mathrm{C}) \mathrm{VCCC}(\mathrm{C})$ syllabic structure) try to adapt the present English syllable based on their phonological knowledge of the syllabic structure that they already internalized. That is the reason for applying some processes such as prothesis, epenthesis, and deletion to make the new item easier to articulate.

\section{Conclusion}

The investigation and assessment of EFL learners' oral production could bring about some new insights about the difficulties that second language learners deal with. Such information helps language teachers to be more sensitive to learners' problems and consequently to take new steps in their teaching methods. In the same route, this study tried to deal with an observed English consonant cluster articulation difficulty of a group of Iranian learners during an English course. To meet this, the research presented some English and Persian syllabic structure and also some reference to Contrastive Analysis Hypothesis to establish some theoretical background. The data collected about the learners' oral production of some consonant clusters that their structures were in sharp contrast with Persian syllabic structure conventions were analyzed. It showed that the differences between the syllable structure of Persian and English would be responsible for pronunciation problems of Iranian learners. Furthermore, this study emphasized that when this group of Persian language learners learning English as foreign language dealt with some syllables not present in their first language structure, they resort to their first language rules to cope with such difficulties. It is necessary to be mentioned that this study can not be generalized. It simply tried to hand in a snapshot of Persian learners' difficulties through investigating a small sample group of a big community.

\section{References}

Brown, H. D. (2007). Principles of language learning and teaching (5 $5^{\text {th }}$ ed.). NewYork: Pearson.

Byrd, D., \& Tan, C.C. (1996). Saying consonant clusters quickly. Journal of Phonetics, 24, $263-282$. http://dx.doi.org/10.1006/jpho.1996.0014

Celce-Murcia, M., Brinton, D.M., Goodwin, J. M., \& Griner, B. (2010). Teaching pronunciation: reference for teachers of English to speakers of other languages $\left(2^{\text {nd }}\right.$ ed.). New York: Cambridge University Press.

Chang, F. C. (2004). Chinese-speaking EFL learners' performances of processing English consonant clusters: International Conference on English Instruction and Assessment. National Chiayi University.

Davies, A., \& Elder, C. (Eds.). (2006). The handbook of applied linguistics. Oxford: Blackwell.

Greenberg, J.H. (2005). Universals of language $\quad\left(2^{\text {nd }} \quad\right.$ ed.). Cambridge: MIT Press. http://dx.doi.org/10.1515/9783110899771

Jabbari, A. A., \& Samavarchi, L. (2011). Persian learners' syllabification of English consonant clusters. International Journal of English Linguistics, 1, 236-246.

Kabak, B., \& Idsardi, W. J. (2007). Perceptual distortions in the adaptation of English consonant clusters: Syllable 
structure or consonantal contact constraints? Language and Speech, 50(1), 23-52. http://dx.doi.org/10.1177/00238309070500010201

Keshavarz, M. H. (2001). A practical course of English phonetics and phonology. Tehran: Scientific and Cultural Publications Company.

Malmkjær, K. (Ed.). (2010). The linguistics encyclopedia ( $3^{\text {rd }}$ ed.). New York: Routledge.

O'Grady, W., Katamba, F., \& Archibald, J. (2011). Contemporary linguistics: An introduction (2 ${ }^{\text {nd }}$ ed.). London: Longman.

Richards, J. C., \& Schmidt, R. (2010). Longman dictionary of language teaching and applied linguistics (4 ${ }^{\text {th }}$ ed.). London: Longman.

Salmani-Nodoushan, M. A. (2006). Phonology and phonetics. US: American Lulu.

Samareh, Y. (1999). The phonetics of Farsi: Sounds and syllable structure. Tehran: University Press Center.

Schreier, D. (2005). Corpus-based evidence of historical change in English phonotactics. International Journal of English Studies, 5(1), 77-99.

Stockwell, R. P., Bowen, J. D., \& Martin, J. W. (1965). The grammatical structures of English and Spanish (2 ${ }^{\text {nd }}$ ed.). Chicago: The University of Chicago Press.

Yarmohammadi, L. (2002). A contrastive analysis of Persian and English: grammar, vocabulary and phonology. Tehran: Payame Noor University.

Ziahosseiny, S. M. (2009). How to compare languages. Contrastive analysis of Persian \& English and error analysis (pp.10-24) ( $3^{\text {rd }}$ ed.). Tehran: Rahnama Press.

\section{Appendix}

Please read the sentences below:

1. I proved that I am not the one who stole the plant.

2. To get a good surfboard, you need to check its strength and breadth.

3. The world around us is nothing but principles and facts.

4. The trainer spoke for the class.

5. There is a scratch on the spray container.

6. I left my clothes in the last flight. 